\title{
Continuous positive airway pressure and humidification
}

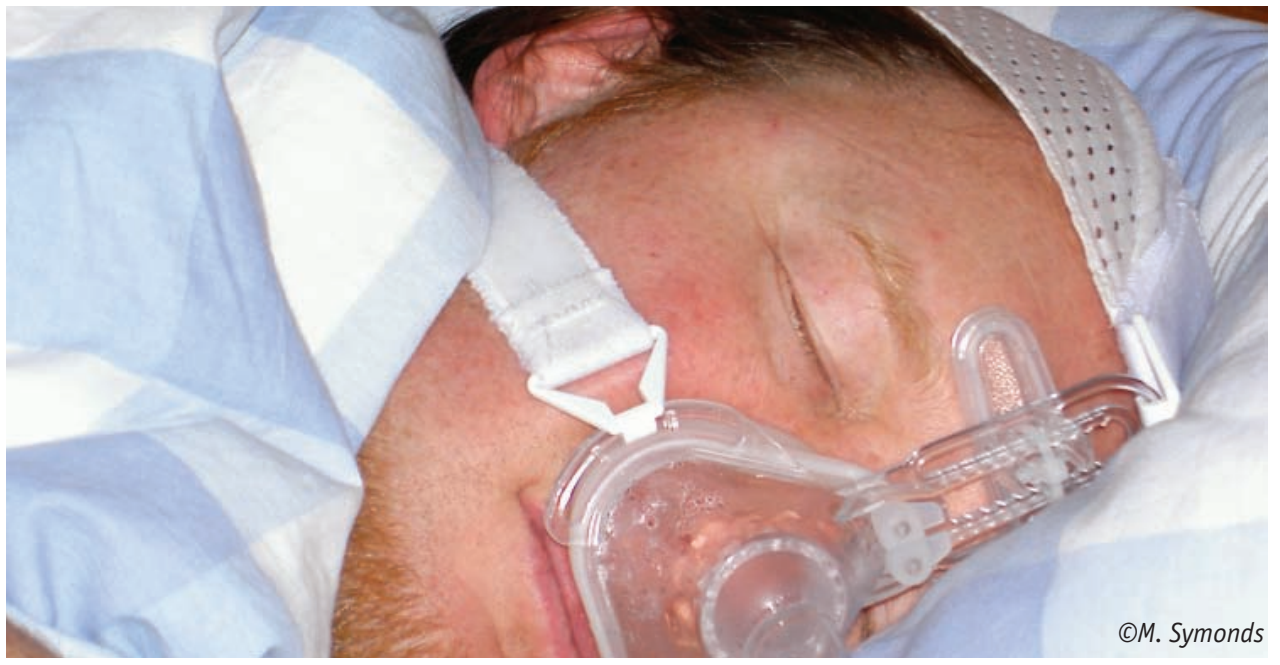

\section{Educational aims}

1 To demonstrate the sideeffects of CPAP on the upper airways.

1 To discuss the principles of humidification of breathing.

1 To explain the operating mode and distinctions of different heated humidifiers.

\section{Summary}

Upper airway complications are very common during noninvasive positive-pressure ventilation, particularly continuous positive airway pressure (CPAP). Acceptance of CPAP is compromised if such complaints occur; thus proactive management is very important for the achievement of good compliance. The use of conventional heated humidifiers is standard therapy when complications with upper airways arise during CPAP therapy. The performance of different types of heated humidifiers has not been fully considered in terms of their therapeutic effect. In particular, changes in ambient conditions should be taken into account. Advanced controlled heated humidifiers with heated breathing tubes monitor the amount of air flow, e.g. when mouth or mask leaks occur, as well as changes in ambient temperature. These more advanced techniques have been proven to reduce side effects.

\section{Introduction}

In recent years, various techniques of artificial ventilation have been subject to widespread debate and discussion in terms of their efficacy and performance. This review will focus on the importance of humidification, with the main emphasis on noninvasive ventilation, particularly CPAP.
G. Nilius

K-H. Ruhle

HELOS Klinik Hagen-Ambrock, Hagen and Universität Witten Herdecke, Witten, Germany

\section{Correspondence}

G. Nilius

HELIOS-Klinik Hagen-Ambrock University of Witten Herdecke Ambroker Weg 60

58455 Hagen

Germany

georg.nilius@helios-kliniken.de

\section{Provenance}

Commissioned article, peer reviewws.

\section{Competing interests}

G. Nilius and K-H. Ruhle have received grants for different studies from Heinen und Löwenstein, Germany, Fisher and Paykel, New Zealand, Resmed, Germany, Respironics UK, Somnomedics, Germany and Weimann, Hamburg, Germany. 
In invasive ventilation, the upper airways are bypassed through an orotracheal tube or tracheal cannula; therefore, the natural humidification of air, which usually takes place in the upper airways, is no longer possible. Consequently, humidification of inspired air is mandatory in all cases of invasive mechanical ventilation, either with a heat and moisture exchange filter or through a heated humidifier $[1,2]$.

In noninvasive ventilation, a passage of air is provided through the upper airway and natural humidification occurs. Subsequent research refers primarily to noninvasive ventilation in the form of CPAP therapy, which has the largest number of users and has been the subject of the most clinical studies.

\section{Obstructive sleep apnoea}

Approximately $2 \%$ of females and $4 \%$ of males of working age currently suffer from obstructive sleep apnoea (OSA) syndrome [3]. Due to repetitive collapse of the upper airway during sleep, patients develop recurrent oxygen desaturations and arousals [4], resulting in nonrestful sleep [5], reduction in the quality of life $[6,7]$, increased rate of road traffic accidents [8], greater risk of developing arterial hypertension [9-11] and a higher risk of mortality from cardiovascular diseases.

The "gold standard" therapy for OSA is CPAP. CPAP prevents the collapse of the upper airway by means of a pneumatic splint. This therapy improves quality of life by reducing the effects of OSA, such as daytime sleepiness and road traffic accidents $[12,13]$. CPAP for $\geq 4 \mathrm{~h}$ per night normalises the risk of mortality [14, 15]. However, it is not known how long the minimum usage per night must be to improve daytime symptoms $[16,17]$ and to have a favourable effect in the long term. It is possible that an average usage of $>1 \mathrm{~h}$ CPAP therapy per night may reduce mortality [18]. For general considerations, total acceptance during the whole night would be desirable to prevent the collapse of the upper airway during the entire sleep time and to minimise the impacts on health as much as possible.

While therapeutic efficacy of CPAP treatment is excellent in sleep laboratories, the effectiveness in daily routine is significantly lower [19-22]. In total, 30-50\% of all patients are not using CPAP treatment consistently in the long term for various reasons. There are no known serious side-effects of CPAP therapy [23, 24]; however, some patients find tight-fitting masks and the higher airway pressure unpleasant. Furthermore, a considerable group of patients complain about mucous membrane problems, such as increased dryness of the upper airways $[25,26]$.

Technical developments in pressure applications, for example auto-adjusting CPAP [27-29], bi-level positive airway pressure [30] and pressure relief CPAP (C-flex) [31], are aimed at reducing the administered positive airway pressure in order to decrease side-effects and subsequently increase acceptance. However, as yet no modification of pressure device can demonstrate superiority compared with fixed pressure systems [32, 33]. Some advantages have been demonstrated in small patient subgroups, such as REM or sleep position-dependent OSA.

The other main technical approach for improving CPAP acceptance, based on the subjective experience of dryness, is the development of humidifying systems. Humidification with CPAP therapy makes treatment more comfortable and helps the patient consistently use CPAP. The following section discusses the fundamental concepts of humidification and how they are applied to CPAP therapy.

\section{Physical background}

Air can only hold a certain amount of water vapour or moisture. This certain amount of water vapour is known as maximum capacity and is influenced by the ambient temperature. The basic principle is the higher the temperature the greater the air capacity to hold water vapour and vice versa. Absolute humidity refers to the amount of water vapour or moisture that exists in the air and is measured in mg per $\mathrm{L}$ (figure 1). Figure 1 shows the relationship between temperature and humidity.

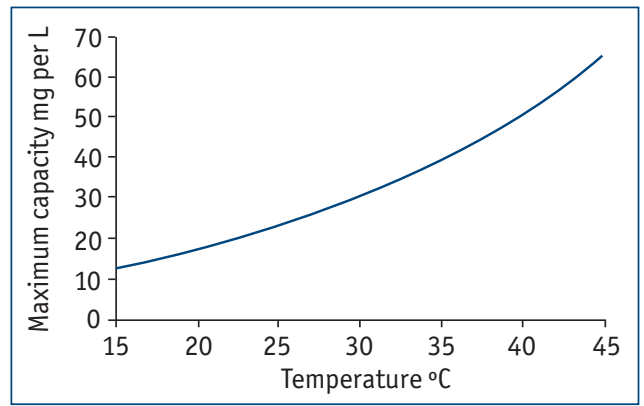

Figure 1

Relationship between temperature and maximum capacity. 
Humidity can also be expressed in relative terms. Relative humidity is the ratio of true water content to maximum possible water content at a certain temperature, expressed as a percentage. Dew point refers to the temperature at which condensation begins to form. This occurs when the ambient temperature drops, causing the amount of moisture in the air to exceed the capacity of moisture that air can hold at that temperature, resulting in condensation.

A good example that can be used to illustrate how condensation develops is on a glass mirror while taking a shower. During a shower, the steam from the hot water increases humidity inside the bathroom to $100 \%$, despite the fact that there is no change in temperature. When the fully saturated air hits the cold surface of the mirror, condensation begins and water droplets appear on the mirror's surface. Modern homes sometimes have a heated element behind the mirror that maintains the surface temperature of the mirror above dew point which prevents condensation from occurring. Another example would be the formation of dew drops on grass, which can be seen early in the morning. As the temperature changes overnight, the moisture laden air hits the cool surface of the grass and results in dew drops.

Changes in temperature significantly affect absolute humidity. This is demonstrated by the following practical example. If the room temperature is $15^{\circ} \mathrm{C}$ and relative humidity is $\angle 50 \%$, then absolute humidity under these conditions is 6 $\mathrm{mg}$ per $\mathrm{L}$. Heat and moisture is added to inhaled air on its way through the airways from the nose to the alveoli, and relative humidity rises to $100 \%$ and $44 \mathrm{mg}$ per $\mathrm{L}$. Thus the air has to absorb $>30$ $\mathrm{mg}$ of water on its way from the nose to the alveoli. The nose is an important water exchanger; it humidifies inhaled air and regains a part of the moisture from exhaled air. The nasophar$y n x$ in the upper nasal cavity is responsible for adding heat and moisture to the inhaled air. It does so through the labyrinth of passages that air must pass through which create turbulence. Turbulence makes it easier for the inhaled air to be conditioned to a moisture level of $30 \mathrm{mg}$ per $L$ at $30^{\circ} \mathrm{C}$ and $90 \%$ relative humidity. Most of the conditioning of the inhaled air occurs at the level of the nasopharynx. As the air passes through the trachea, the inhaled air is further humidified to $\sim 42 \mathrm{mg}$ per $\mathrm{L}$ at $36^{\circ} \mathrm{C}$ and $100 \%$ relative humidity. Therefore, by the time the air reaches the alveoli the air is fully saturated to 44 mg per $\mathrm{L}$ at $37^{\circ} \mathrm{C}$, reaching the core body temperature [34].

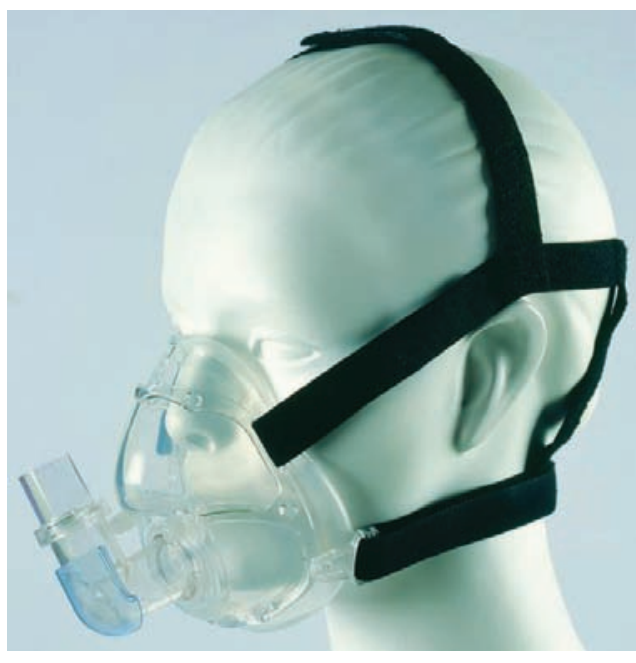

\section{Humidity and CPAP}

Experimental data show that there is a drop in absolute humidity at the anterior turbinate area of the nose from $17.4 \pm 3.8$ to $15.3 \pm 2.3 \mathrm{mg}$ per $\mathrm{L}$ under a CPAP pressure of $8 \mathrm{cmH}_{2} \mathrm{O}$ [35]. When simulating a leak in the mask, the increased air flow causes an additional drop in humidity to $13.8 \pm 2.3 \mathrm{mg}$ per $\mathrm{L}$. This can be alleviated by a heated humidifier. To compensate for the high air flow, it is imperative that the air delivered via CPAP is humidified in order to avoid patient discomfort.

A particular burden on nasal mucosal membranes is the occurrence of a mouth leak, which results in a high unidirectional air flow in the nose and out through the mouth [36]. When experimentally simulating a mouth leak, nasal mucosal membranes dry out quickly; this subsequently increases the blood circulation around the mucous membranes, causing the resistance to air flow to increase severely [37]. Mouth leaks are predominantly seen when the patient uses a nasal mask [38]. To accommodate mouth breathers, full face masks can also be used. However, it is not always possible to convert nasal mask users to full face masks and they could continue to experience feelings of claustrophobia and reduced acceptance of CPAP [39]. The only reliable solution is to use humidification alongside CPAP therapy.

\section{Physics of humidifica- tion}

Humidification is based on a process called free evaporation, which is the principle of water molecules colliding and having sufficient energy to 
escape the liquid as water vapour. The process of free evaporation can be achieved by increasing air-water surface area and air-flow mass and by raising the temperature of the water. A conventional heated humidifier consists of a regulated heater plate that heats a water bath. The air stream travels over the warmed water where it absorbs heat and moisture.

The amount of humidity delivered by a CPAP system is very dependent on the ambient temperature and the amount of air flow. Modern humidification systems are designed to monitor both ambient conditions and air flow within the system to ensure the right amount of humidity is delivered. An algorithm that enables a subjective default adjustment considers ambient measurements and adjusts the temperature of the heater plate accordingly. Changing ambient conditions need to be factored into the design of the humidifier to prevent water condensation in the breathing tube; this is especially prevalent in colder environments.

A method that is used to overcome the limitations of humidification is to combine the humidifier with a heated tube. The temperature inside the tube is controlled by a copper wire, which coils around the walls of the tube. By maintaining a constant temperature along the length of the tube, the humidified gas is isolated from the influences of changing ambient conditions and condensation in the tube is prevented. This means that no moisture or humidity is lost as the gas travels along the length of the tube.

\section{Clinical benefit of humidifiers}

Cold pass-over systems are inferior to heated humidifying systems and have not achieved clinical relevance [40]. Various studies have analysed the effects of heated humidification on acceptance and side-effects of CPAP therapy [41]. The results are variable and inconclusive. While a general increase in CPAP acceptance in one randomised prospective study was shown [42], other studies failed to prove such an effect $[43,44]$. There is no clear explanation for this variety of results, but it should be noted that the optimum level of humidification needed to reliably reduce the side-effects of CPAP therapy affecting the mucosa and the upper airways is not yet known. The performances of most conventional heated humidifiers, which can be combined with a CPAP device, vary significantly [45]. In summary, it can be said that it is possible to reduce the extent of upper airway discomfort with heated humidification; however, present studies show no general increase in the use of CPAP therapy.

Everyday experience shows that side-effects affecting the mucous membranes are to be expected in approximately one third of all patients treated with CPAP. Specific risk groups for the occurrence of such disorders are those who have undergone an uvulopalatopharnyngoplasty, have a nasal medical history or who take medication, all of which have an impact on nasal blood

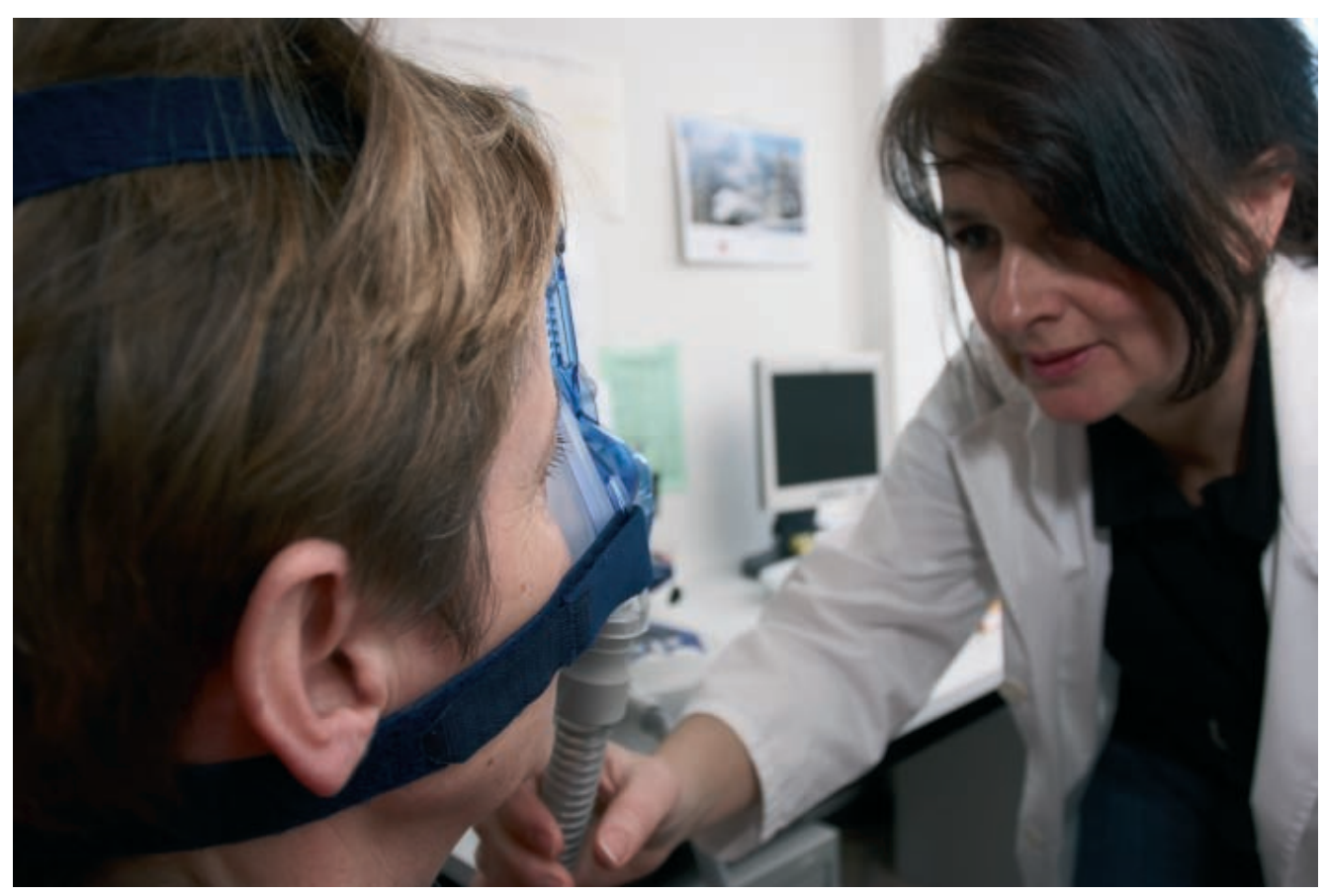


circulation [46]. Several studies have shown that when upper airway disorders occur during CPAP therapy, the extent of these complaints could be reduced by the application of a heated humidifier [47], which leads to an increase in everyday use of CPAP. For practical purposes a step concept proved successful: when problems occur after an initial conservative CPAP trial, it is the standard practice to apply heated humidifiers [48].

Limited research exists on the use of heated breathing tubes during CPAP therapy. A study by Nitus et al. [49] measured the effect of a conventional humidifier added to CPAP compared with a controlled heated breathing tube on sleep quality during two separate nights in the sleep laboratory. The study found that a heated breathing tube improved patient sleep quality (increased total sleep time, REM and stage 3/4 sleep). It also showed reduced side-effects with heated breathing tubes. These findings are important as they provide a true measure of therapy. Compliance is a useful outcome measure; however, it only relates to use, not to sleep. Theoretically, a patient can be compliant on their device, but awake all night. This research indicates that higher levels of humidity actually improve the quality of sleep, proving it to be a strong outcome measure.

A recent study by MASSENGIIL and LewIS [50] investigated the effect humidification has on titrated CPAP therapy in a controlled laboratory environment. The group found that with heated breathing tubes the average titrated pressure was $1.1 \mathrm{cmH}_{2} \mathrm{O}$, lower than titrating patients without the heated breathing tube. The proposed mechanism of action for this reduction was a decrease in nasal airway resistance with heated breathing tubes. This is an interesting finding, which should be investigated its importance in the role of CPAP titration. While the studies are limited and small in number, they show some noteworthy outcomes that are prospects for future research.

\section{Side-effects}

Two main disadvantages of heated humidifiers have to be considered.

\section{Infections}

While various older studies do not show any evidence of increased bacterial transfer from the water reservoir to the air breathed [51], a newer survey proved such an association [52]. However, it is not clear if this finding has clinical relevance. A possible bacterial colonisation in the mask, tube or humidifier has to be considered when infections appear. Protection with a hydrophobic breathing filter may prevent such transmission. In particular, patients who do not follow hygienic recommendations seem to show a slightly increased risk of infection [53].

\section{Condensation}

The cooling down of the humidified air in the tube system after it has passed through the humidifier results in a reduction in the absolute level of water which can be dissolved in the gaseous phase in the air. If the temperature of the gas falls below the dew point, some of the moisture will condense in the tube. Depending on the level of water in the tube, the effective breathing pressure may fall distal to the stenosis and may compromise the quality of ventilation. As the air from CPAP passes over the condensate inside the tube, fluctuations in delivered pressure can be seen due to the increased resistance in the circuit. A study by BACon et al. [54] showed that the pressure can fluctuate by as much $5.6 \mathrm{cmH}_{2} \mathrm{O}$ with as little as $10 \mathrm{~mL}$ of condensate inside the tube. Not only does the pressure fluctuate dramatically but gurgling noises can also stem from the accumulation of condensation. These noises can be disruptive to the patient and their bed partners, resulting in poor quality of treatment [49]. If condensation persists every night, this could cause the patient to abandon the therapy for good.

\section{Technical aspects of a good humidification system}

In short, a good humidifier is one that is able to deliver adequate levels of humidification without causing condensation or rain out. A heated humidification system typically comprises a chamber containing water and a heater plate, with some systems also having a heated breathing tube.

The chamber or reservoir should be designed to hold sufficient water to last one full night of use. Some chambers have a baffle on the interior, which is designed to split the stream of air generated by CPAP in order to increase the surface area contact between air and water. The baffle, combined with the air flow, helps mix the air and water which is created by the turbulence generated by the air stream. Again, it is this turbulence that aids in collecting the moisture and delivering it to the patient. 
Critical to the delivery of optimal humidity is a high-performance heater plate, normally made of stainless steel, which is responsible for transferring thermal energy to the water contained inside the reservoir. A good heater plate heats the water as quickly as possible so that high levels of humidity are delivered to the patient from the outset of therapy.

A heated breathing tube assists in the delivery of high levels of humidity without condensation changing ambient conditions. If the power supplied to the heater plate and heated breathing tube is insufficient, it is highly likely that rain out will occur. Therefore, low-powered humidifiers are more susceptible to rain out when overnight temperatures decrease.

CPAPs without a heated breathing tube may be limited to delivering gas at room temperature. This means they can only deliver gas at the maximum saturation of the room temperature. Trying to deliver gas above this temperature will cause rain out as the gas cools to room temperature in the nonheated tube. A recent bench study showed that conventional humidifiers were only able to achieve $18 \mathrm{mg}$ per $\mathrm{L}$ (absolute humidity) at $22^{\circ} \mathrm{C}$ (room temperature) while heated humidification with a heated breathing tube is able to reach $28 \mathrm{mg}$ per $\mathrm{L}$ without condensation [55].

\section{Conclusion}

If nasopharyngeal side-effects occur sufficient humidification is of great importance in order to ensure that a patient receives effective CPAP therapy. Delivering effective CPAP therapy is the only noninvasive treatment option available, which needs to be sustained for the lifetime of the patient once diagnosed with OSA. Since most patients find CPAP an unnatural experience to start with, it is important that an effective humidification system reinforces CPAP therapy to make it a comfortable and natural experience.

\section{References}

1. Kola A, Eckmanns T, Gastmeier P. Efficacy of heat-and-moisture exchangers in preventing ventilator-associated pneumonia: meta-analysis of randomized controlled trials. Intensive Care Med 2005; 31: 5-11.

2. Siempos II, Vardakas KZ, Kopterides $\mathrm{P}$, et al. Impact of passive humidification on clinical outcomes of mechanically ventilated patients: a meta-analysis of randomized controlled trials. Crit Care Med 2007; 35: 2843-2851.

3. Young T, Palta M, Dempsey J, et al. The occurrence of sleep-disordered breathing among middle-aged adults. $N$ Engl J Med 1993; 328: 1230-1235.

4. Iber C, Ancoli-Israel S, Chesson AL, et al. The AASM Manual for the Scoring of Sleep and Associated Events: Rules, Terminology and Technical Specifications. Westchester, American Academy of Sleep Medicine, 2007.

5. Weaver TE, Laizner AM, Evans LK et al. An instrument to measure functional status outcomes for disorders of excessive sleepiness. Sleep 1997; 20: 835-843.

6. Lacasse Y, Bureau MP, Series F. A new standardised and self-administered quality of life questionnaire specific to obstructive sleep apnoea. Thorax 2004; 59: 494-499.

7. Sanner B, Klewer J, Trumm A, et al. Long-term treatment with continuous positive airway pressure improves quality of life in obstructive sleep apnoea syndrome. Eur Respir J 2000; 16: 118-122.

8. Barbé F, Pericás J, Muñoz A, et al. Automobile accidents in patients with sleep apnoea syndrome. Am J Respir Crit Care Med 1998; 158: 18-22.

9. Young T, Peppard P, Palta M, et al. Population-based study of sleep-disordered breathing as a risk factor for hypertension. Arch Intern Med 1997; 157: 1746-1752.

10. Becker HF, Jerrentrup A, Ploch T, et al. Effect of nasal continuous positive airway pressure treatment on blood pressure in patients with obstructive sleep apnea. Circulation 2003 7; 107: 68-73.

11. Young T, Peppard P, Palta M, et al. Population-based study of sleep-disordered breathing as a risk factor for hypertension. Arch Intern Med 1997; 157: 1746-1752.

12. Sassani A, Findley LJ, Kryger M, et al. Reducing motor-vehicle collisions, costs and fatalities by treating obstructive sleep apnea syndrome. Sleep 2004; 27: 453-458.

13. George CF. Reduction in motor vehicle collisions following treatment of sleep apnoea with nasal CPAP. Thorax 2001; 56: 508-512.

14. Marin JM, Carrizo SJ, Vicente E, et al. Long-term cardiovascular outcomes in men with obstructive sleep apnoea-hypopnoea with or without treatment with continuous positive airway pressure: an observational study. Lancet 2005; 365: 1046-1053.

15. Buchner NJ, Sanner BM, Borgel J, et al. Continuous positive airway pressure treatment of mild to moderate obstructive sleep apnea reduces cardiovascular risk. Am J Respir Crit Care Med 2007; 176: 1274-1280.

16. McNicholas WT. Compliance with nasal CPAP therapy for obstructive sleep apnea; how much is enough? Eur Respir J 1997; 10: 973-976.

17. Weaver TE, Maislin G, Dinges DF, et al. Relationship between hours of CPAP use and achieving normal levels of sleepiness and daily functioning. Sleep 2007; 30: 711-719.

18. Campos-Rodriguez F, Perez-Ronchel J, et al. Long-term effect of continuous positive airway pressure on BP in patients with hypertension and sleep apnea. Chest 2007; 132: 1847-1852.

19. Pieters T, Collard P, Aubert G, et al. Acceptance and long-term compliance with nCPAP in patients with obstructive sleep apnoea syndrome. Eur Respir J 1996; 9: 939-944.

20. Engleman HM, Asgari-Jirhandeh N, McLeod AL, et al. Self-reported use of CPAP and benefits of CPAP therapy: a patient survey. Chest 1996; 109: 1470-1476. 
21. Meurice JC, Dore P, Paquereau J, et al. Predictive factors of long-term compliance with nasal positive airway pressure treatment in sleep apnea syndrome. Chest 1994; 105: 429-433.

22. McArdle N, Devereux G, Heidarnejad H, et al. Long-term use of CPAP therapy for sleep apnea/hypopnea syndrome. Am J Respir Crit Care Med 1999; 159: 1108-1114.

23. Pepin JL, Leger P, Veale $D$, et al. Side effects of nasal continuous positive airway pressure in sleep apnea syndrome. Study of 193 patients in two French sleep centers. Chest 1995; 107: 375-381.

24. Engleman HM, Asgari-Jirhandeh N, McLeod AL, et al. Self-reported use of CPAP and benefits of CPAP therapy: a patient survey. Chest 1996; 109: 1470-1476.

25. Nilius G, Franke KJ, Domanski U, et al. Upper airway complaints of patients with obstructive sleep apnea - effect of CPAP. Pneumologie 2007; 61: 15-19.

26. Lojander J, Brander PE, Ämmälä K. Nasopharyngeal symptoms and nasal continuous positive airway pressure therapy in obstructive sleep apnoea syndrome. Acta Otolaryngol 1999; 119: 497-502.

27. Teschler $\mathrm{H}$, Berthon-Jones $\mathrm{M}$, Thompson AB, et al. Automated continuous positive airway pressure titration for obstructive sleep apnea syndrome. Am J Respir Crit Care Med 1996; 154: 734-740.

28. Randerath WJ, Schraeder 0 , Galetke W, et al. Auto-adjusting CPAP therapy based on impedance efficacy, compliance and acceptance. Am J Respir Crit Care Med 2001; 163: 652-657.

29. D'Ortho MP, Grillier-Lanoir V, Levy P, et al. Constant versus automatic continuous positive airway pressure therapy: home evaluation. Chest 2000; 118: 1010-1017.

30. Gay PC, Herold DL, Olson EJ. A randomized, double-blind clinical trial comparing continuous positive airway pressure with a novel bi-level pressure system for treatment of obstructive sleep apnea syndrome. Sleep 2003; 26: 864-869.

31. Nilius G, Happel A, Domanski U, et al. Pressure-relief continuous positive airway pressure versus constant continuous positive airway pressure. A comparison of efficacy and compliance. Chest 2006; 130: 1018-1024.

32. Kakkar RK, Berry RB. Positive airway pressure treatment for obstructive sleep apnea. Chest 2007; 132: 1057-1072.

33. Smith I, Lasserson TJ. Pressure modification for improving usage of continuous positive airway pressure machines in adults with obstructive sleep apnea. Cochrane Database Syst Rev 2009; 4: CD003531.

34. Chiumello D, Chierichetti M, Tallarini F, et al. Effect of a heated humidifier during continuous positive airway pressure delivered by a helmet. Crit Care 2008; 12: R55.

35. Fischer Y, Keck T, Leiacker R, et al. Effects of nasal mask leak and heated humidification on nasal mucosa in the therapy with nasal continuous positive airway pressure (nCPAP). Sleep Breath 2008; 12: 353-357.

36. Richards GN, Cistulli PA, Ungar G, et al. Mouth leak with nasal continuous positive airway pressure increases nasal airway resistance. Am J Respir Crit Care Med 1996; 154: 182-186.

37. Hayes MJ, McGregor FB, Roberts DN, et al. Continuous nasal positive airway pressure with a mouth leak: effect on nasal mucosal blood flux and nasal geometry. Thorax 1995; 50: 179-182.

38. Martins de Araujo MT, Vieira SB, Vasquez EC, et al. Heated humidification or face mask to prevent upper airway dryness during continuous positive airway pressure therapy. Chest 2000; 117: 142-147.

39. Chai CL, Pathinathan A, Smith B. Continuous positive airway pressure delivery interfaces for obstructive sleep. Cochrane Database Syst Rev 2006; 18: CD005308.

40. Randerath WJ, Meier J, Genger H, et al. Efficiency of cold pass-over and heated humidification under continuous positive airway pressure. Eur Respir J 2002; 20: 183-186.

41. Wiest GH, Harsch IA, Fuchs FS, et al. Initiation of CPAP therapy for OSA: does prophylactic humidification during CPAP pressure titration improve initial patient acceptance and comfort? Respiration 2002; 69: 406-412.

42. Massie CA, Hart RW, Peralez K, et al. Effects of humidification on nasal symptoms and compliance in sleep apnea patients using continuous positive airway pressure. Chest 1999; 116: 403-408.

43. Mador MJ, Krauza M, Pervez A, et al. Effect of heated humidification on compliance and quality of life in patients with sleep apnea using nasal continuous positive airway pressure. Chest 2005; 128: 2151-2158.

44. Duong M, Jayaram L, Camfferman D, et al. Use of heated humidification during nasal CPAP titration in obstructive sleep apnoea syndrome. Eur Respir J 2005; 26: 679-685.

45. Wenzel M, Wenzel G, Klauke M, et al. Characteristics of several humidifiers for CPAP-therapy, invasive and noninvasive ventilation and oxygen therapy under standardised climatic conditions in a climatic chamber. Pneumologie 2008; 62: 324-329.

46. Rakotonanahary D, Pelletier-Fleury N, Gagnadoux F, et al. Predictive factors for the need for additional humidification during nasal continuous positive airway pressure therapy. Chest 2001; 119: 460-465.

47. Worsnop CJ, Miseski S, Rochford PD. The routine use of humidification with nasal continuous positive airway pressure. Intern Med J 2009; [Epub ahead of print DOI: 10.1111/j.1445-5994.2009.01969.x].

48. Ballard RD, Gay PC, Strollo PJ. Interventions to improve compliance in sleep apnea patients previously non-compliant with continuous positive airway pressure. J Clin Sleep Med 2007; 15; 706-712.

49. Nilius G, Domanski U, Franke KJ, et al. Impact of a controlled heated breathing tube humidifier on sleep quality during CPAP therapy in a cool sleeping environment. Eur Respir J 2008; 31: 830-836.

50. Massengill JS, Lewis KL. Effect of humidification on titration pressures in obstructive sleep apnea. Sleep 2009; 32 : A217.

51. Wenzel M, Klauke M, Gessenhardt F, et al. Sterile water is unnecessary in a continuous positive airway pressure convection-type humidifier in the treatment of obstructive sleep apnea syndrome. Chest 2005; 128: 2138-2140.

52. Ortolano GA, Schaffer J, McAlister MB, et al. Filters reduce the risk of bacterial transmission from contaminated heated humidifiers used with CPAP for obstructive sleep apnea. J Clin Sleep Med 2007; 3: 700-705.

53. Sanner BM, Fluerenbrock N, Kleiber-Imbeck A, et al. Effect of continuous positive airway pressure therapy on infectious complications in patients with obstructive sleep apnea syndrome. Respiration 2001; 68: 483-487.

54. Bacon JP, Farney RJ, Jensen RL, et al. Nasal continuous positive airway pressure devices do not maintain the set pressure dynamically when tested under simulated clinical conditions. Chest 2000; 118: 1441-1449.

55. Virag R. Evaluation of the performance of CPAP heated humidifiers for use in sleep apnea therapy: a comparative study of humidification effectiveness. Sleep 2008. 31: A382. 